\title{
Genetic Variability in Partitioning to the Yield Component of Cacao (Theobroma cacao L.)
}

\author{
A.J. Daymond ${ }^{1}$ and P. Hadley \\ Department of Horticulture and Landscape, School of Plant Sciences, The \\ University of Reading, Whiteknights, Reading, RG6 6AS, UK \\ R.C.R. Machado \\ Almirante Centre For Cocoa Studies, Fazenda Almirante, CX. Postal 55 CEP \\ 45653-000, Itajuipe, Bahia, Brazil
}

E. Ng

Mars Inc., 6885 Elm Street, McLean, VA 22101

Additional index words. clone, hybrid, yield efficiency

\begin{abstract}
Biomass partitioning of cacao (Theobroma cacao L.) was studied in seven clones and five hybrids in a replicated experiment in Bahia, Brazil. Over an 18-month period, a 7 -fold difference in dry bean yield was demonstrated between genotypes, ranging from the equivalent of 200 to $1389 \mathrm{~kg} \cdot \mathrm{ha}^{-1}$. During the same interval, the increase in trunk crosssectional area ranged from $11.1 \mathrm{~cm}^{2}$ for clone EEG-29 to $27.6 \mathrm{~cm}^{2}$ for hybrid PA-150 x MA15. Yield efficiency increment (the ratio of cumulative yield to the increase in trunk circumference), which indicated partitioning between the vegetative and reproductive components, ranged from $0.008 \mathrm{~kg} \cdot \mathrm{cm}^{-2}$ for clone $C P-82$ to $0.08 \mathrm{~kg} \cdot \mathrm{cm}^{-2}$ for clone EEG-29. An examination of biomass partitioning within the pod of the seven clones revealed that the beans accounted for between $32.0 \%$ (CP-82) and $44.5 \%$ (ICS-9) of the pod biomass. The study demonstrated the potential for yield improvement in cacao by selectively breeding for more efficient partitioning to the yield component.
\end{abstract}

An increase in yield of tree crops associated with more efficient partitioning of dry matter to the yield component (e.g., Fallahi et al., 1994) is a factor that may be exploited in breeding programs. The tropical tree crop cacao (Theobroma cacao L.) shows considerable genotypic variability in morphological and physiological traits associated with yield (Yapp and Hadley, 1994), but this variability has only been exploited to a limited extent. Measurement of dry matter increase and partitioning in a tree species such as cacao is complicated by the fact that destructive analysis is often not practical and therefore a nondestructive index of vegetative growth is needed. A number of studies of tree crops have applied the concept of "yield efficiency," defined as the ratio of cumulative yield to cross-sectional trunk area (for example, Hill et al., 1987; Larsen and Fritts, 1982, 1987; Larsen et al., 1992). Here, a similar concept is applied to cacao, whereby yield over a discrete period of time is considered in relation to trunk growth over the same period to produce a yield efficiency increment.

Received for publication 9 July 2001. Accepted for publication $10 \mathrm{Feb}$. 2002. The authors thank the staff of the Agronomy section at the Almirante Centre for Cocoa Studies for technical help. This work was funded by M\&M/Mars.

${ }^{1}$ To whom reprint requests should be addressed. Tel. 0044118931 6467; Fax. 0044118975 0630; e-mail: a.j.daymond@reading.ac.uk
An additional consideration in cacao is that only a portion of the harvested pods (i.e., the beans) is of primary economic importance, although pod husks may have secondary uses for livestock feed (de Alba and Basadre, 1952; de Alba et al., 1954) and fertilizer (Ahenkorah et al., 1981). Therefore, the proportion of the pod accounted for by the beans represents another component of biomass partitioning that needs to be considered in an analysis of genetic variability of the efficiency of partitioning to the yield component.

This study focuses on a field experiment consisting of replicated, clonally propagated genotypes known to vary in yield potential. The extent of genetic variability in partitioning to the yield component is considered in two respects: partitioning between vegetative growth and the yield component, and partitioning within the reproductive component.

\section{Materials and Methods}

Study site. The experiment comprised plots of seven clones (CC-10, CP-82, CP-519, EEG29, EET-62, ICS-9, SGU-54) and five hybrids (EEG-65 x ICS-8, ICS-1 x SIC-23, PA-150 x MA-15, P-7 x CP-15, P-7 x ICS-8), replicated in two adjacent blocks ( 30 trees per plot at $3 \mathrm{~m}$ spacing). Tree density was the equivalent to 1111 trees per hectare. The site was located on a hill with "block-1" above "block-2." The location of the experiment was the Almirante Centre For Cocoa Studies, Bahia, Brazil (lat. $14^{\circ} 43.13^{\prime} \mathrm{S}$, long. $\left.39^{\circ} 22.00 \mathrm{~W}\right)$. Cacao trees were 7 years old at the beginning of the data collection period and were lightly shaded throughout the experiment by Glyricidia sp. at a spacing of $6 \mathrm{~m}$. Cultural practices, e.g., chupon removal and weeding were the same throughout the site.

Yield and pod components. Yield data were collected monthly between Sept. 1997 and Mar. 1999, although less frequent collections were made during periods of low productivity. Bean fresh weight was determined from all pods harvested from a given plot, and bean dry weight estimated by multiplying fresh weights by the dry matter content of the beans, which was determined for each cultivar. Potential yield $\left(\mathrm{Y}_{\mathrm{p}}\right)$ per plot was estimated by adjusting for pod losses from black-pod (Phytophythora sp.) and witches' broom disease (Crinipellis perniciosa) according to Eq. [1].

$\mathrm{Y}_{\mathrm{p}}=\mathrm{Y}_{\mathrm{H}} \times\left(\mathrm{P}_{\mathrm{T}} / \mathrm{P}_{\mathrm{H}}\right)$

where " $\mathrm{Y}_{\mathrm{H}}$ " is the yield of healthy pods in $\mathrm{kg}$ dry weight, " $\mathrm{P}_{\mathrm{T}}$ " is the total number of pods harvested and " $\mathrm{P}_{\mathrm{H}}$ " is the number of healthy pods harvested.

Potential yield per tree (" $\mathrm{Y}_{\mathrm{pt}}$ " in $\mathrm{kg}$ dry weight) was then calculated by dividing " $Y_{p}$ " by the number of trees per plot (usually 30 ).

At monthly intervals, between Apr. and July 1999 , the ratio of bean to pod husk dry weight was recorded for each of the seven clones by separating up to five healthy pods (according to availability) from each plot and drying the bean and husk components $\left(60^{\circ} \mathrm{C}\right.$ for $7 \mathrm{~d}$ in a fan-assisted oven) before weighing them.

Vegetative growth and yield efficiency. Trunk circumference of all the trees in the study site was measured at a height of $20 \mathrm{~cm}$ above the ground using a flexible measure. Measurements were made on 16 and 17 Sept. 1997 (T1) and repeated at the same position on each tree on 17-18 Mar. 1999 (T2). Trunk growth increment (TGI) was calculated according to Eq. [2] and yield efficiency increment (YEI) according to Eq. [3].

$\mathrm{TGI}=\mathrm{TC}_{2}-\mathrm{TC}_{1}$

where, " $\mathrm{TC}_{2}$ " and " $\mathrm{TC}_{1}$ " are trunk cross-sectional area at times $\mathrm{T} 2$ and $\mathrm{T} 1$, respectively.

$\mathrm{YEI}=\mathrm{Y}_{\mathrm{pt}} / \mathrm{TGI}$

Statistical analysis. Trunk growth data were analyzed by means of a two-way analysis of variance (ANOVA) with genotype and block as factors and individual trees as replicates. A $t$ test was used to identify which clones were responsible for any block effects. Yield data and yield efficiency increment were analyzed by means of a one-way ANOVA with genotype as a factor and the blocks as replicates. Regression analysis was used to test for the degree of similarity between blocks in yield, trunk growth and yield efficiency increment and to test for any relationship between trunk growth and yield. Pod component data were analyzed by means of a one-way ANOVA for the effect of genotype, with pods as replicates. All analyses were carried out using GENSTAT. 
Results

Yield. During the 18-month period of the experiment, cumulative potential yield varied 7-fold between clones, with bean dry weight ranging from 0.18 to $1.25 \mathrm{~kg}$ per tree for $\mathrm{CP}$ 82 and EET-65 $\times$ ICS-8, respectively $(P<$ 0.001 ; Fig 1a), which is equivalent to a dry bean yield of 200 to $1389 \mathrm{~kg} \cdot \mathrm{ha}^{-1}$.

Vegetative growth. Considerable variation was noted between clones in trunk growth increment between Sept. 1997 and Mar. 1999; the range was from $11.1 \mathrm{~cm}^{2}$ for EEG-29 to $27.6 \mathrm{~cm}^{2}$ for PA-150 x MA-15 $(P<0.001$; Fig. 1b). Overall differences between blocks were not significant but the clone $\times$ block interaction term showed significant differences. A clone by clone $t$ test analysis demonstrated that two clones (CC-10 and CP-82) had a faster rate of growth in block-2 than block-1 $(P$ $<0.001$ in all cases) and that three genotypes $(\mathrm{P}-7 \times$ CP-15, ICS-1 x SIC-23, SGU-54) had a faster growth rate in block-1 than block- $2(P<$ 0.05 in all cases).

No correlation was found in either block between trunk growth increment and yield.

Yield efficiency. Significant differences between genotypes were detected in yield efficiency increment, ranging from 0.008 $\mathrm{kg} \cdot \mathrm{cm}^{-2}$ for $\mathrm{CP}-82$ to $0.080 \mathrm{~kg} \cdot \mathrm{cm}^{-2}$ for EEG$29(P<0.001$, Fig. 1c). Regression analysis showed that yield increments were strongly correlated between the two blocks $\left(r^{2}=0.79\right)$ and this correlation was stronger than when either yield or trunk growth increment were considered separately $\left(r^{2}=0.56\right.$ and not significant respectively).

Pod components. The proportion of the pod accounted for by the beans (on a dryweight basis) varied from $32 \%$ for CP-82 to $44.5 \%$ for ICS-9 $(P<0.001$; Fig. 2$)$, indicating genetic variability in partitioning within the pod component.

\section{Discussion}

The considerable variation in yield potential that exists in cacao is well illustrated here; a 7-fold difference was observed between the lowest and highest yielding genotypes. The absolute values for yield were lower than found in other published comparative studies of genotypic yield variation (Lockwood and Yin, 1996; Yapp, 1992) reflecting the suboptimal (i.e., low input) conditions of this region. Such conditions, however, are more typical of the majority of cacao cultivation; typical dry bean yields in Bahia (before the onset of witches' broom disease in 1989) have been reported in the region of $590 \mathrm{~kg} \cdot \mathrm{ha}^{-1} /$ year (Lass and Purdy, 1993). Whilst the genotypes used in the present study are not currently widely used as commercial cultivars the potential for yield improvement through genotypic selection was demonstrated under these conditions.

Genetic variability in vegetative growth, as expressed by trunk growth was also evident. Yapp (1992), studying a different range of cacao hybrids, also demonstrated significant variability in trunk girth. Whilst Glendinning

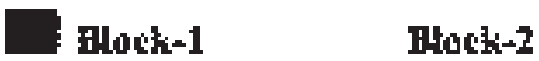

1.50

5
5
5
5
5
5
5
5
5
5

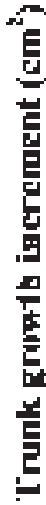

50

b

40

30

26

10

)

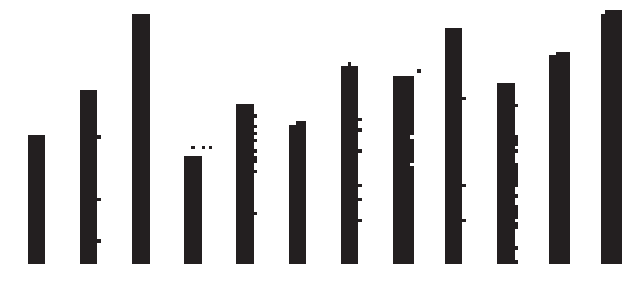

員

9. 10

0.105

9.0.6

0.04

0.02

0.010

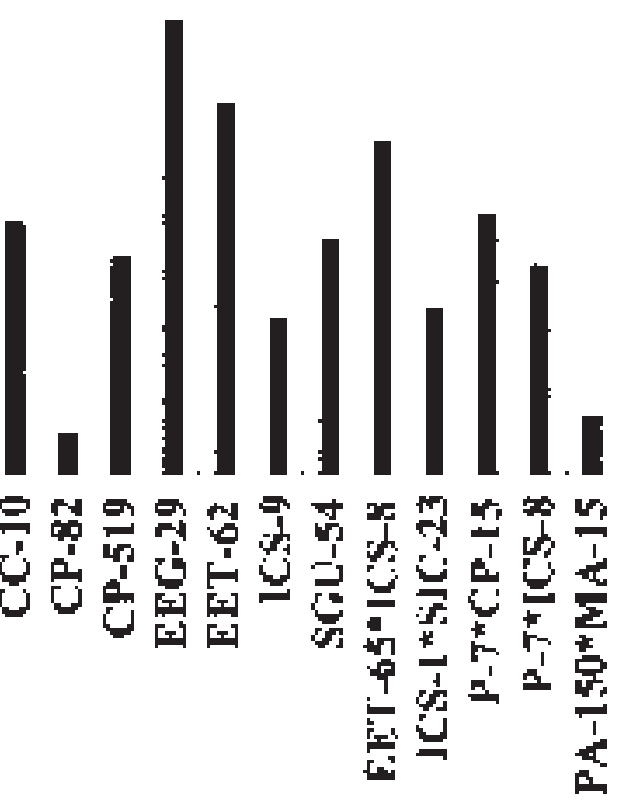

Fig. 1. (a) Cumulative potential yield; (b) trunk growth increment; and (c) yield efficiency increment of seven clones and five hybrids between Sept. 1997, and Mar. 1999. Yield data were calculated from pooled data within a plot; trunk growth increment data are the means of up to 30 trees ( \pm standard errors) and yield efficiency increment data were calculated from mean trunk growth and pooled yield data. 


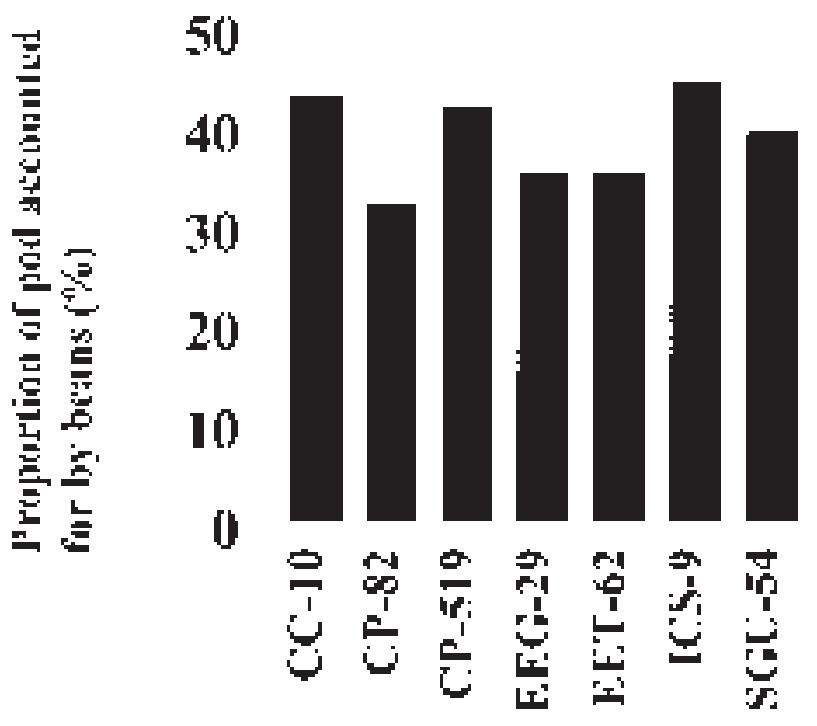

Fig. 2. Interclonal differences in the proportion of the pod dry weight accounted for by the bean. Each point represents the mean of up to 28 replicates ( \pm standard errors).

(1966) observed a negative correlation between trunk growth increment and yield amongst a selection of cacao clones in the bearing phase, no such correlation was found in the present study. Nevertheless, the large variation observed here in the ratio of yield to trunk growth amongst clones implies considerable genetic variation in partitioning to the yield component. The relationship between trunk cross-sectional area and vegetative growth will not be exactly the same for all genotypes due to variability in such factors as branching structure, leaf number, and root turnover. However, the observed differences between genotypes were so great that errors resulting from the methodology are likely to be relatively small and results suggest that a large proportion of the variability in yield between genotypes could be explained by variation in the ratio of yield to vegetative growth.

Some evidence was found for genotype $x$ environment interaction in that a few genotypes exhibited different rates of trunk growth in the two blocks (probably because the topography of block-1 was less even being located on the upper part of a hill). However, reductions in vegetative growth were also associated with reductions in yield so that partitioning was less variable for a given clone between the two blocks. Clearly, genotypes vary in their partitioning between vegetative and reproductive components regardless of whether there is an interaction between genotypes and their environment in their assimilate production.

The range of interclonal differences in the percentage bean dry weight per pod observed (35.3\% to $44.5 \%)$ is less than that observed by Yapp (1992) (43\% to 57\%) for a different set of genotypes. These results illustrate that, in cacao, two partitioning components (the ratio of reproductive to vegetative growth and the ratio of beans to husk) contribute to the variability in yield. Potential yield improvements may be achieved by selecting for a greater pod load and for more efficient pods, i.e., clones that have a greater bean to pod ratio. However, pod thickness can influence the susceptibility to pests, particularly cacao pod borer (Conopomorpha cramerella Snellen) (Azhar et al., 1995), and clearly needs to be taken into account in breeding programs.

Genetic variability has been observed in canopy characteristics and consequently rates of assimilate production in cacao. For example, canopy density (leaf area index) and canopy architecture varied considerably between clonally propagated genotypes (Yapp and Hadley, 1994). The present study suggests that genetic differences in biomass partitioning, principally between vegetative and pod growth and also within the pod itself, are superimposed on differences in assimilate production. Considerable potential therefore ex- ists for yield improvement in cacao by selectively breeding for more efficient partitioning.

\section{Literature Cited}

Ahenkorah, Y., B.J. Halm, and R.S. Amonoo. 1981. Cacao pod husk as source of potash fertilizer. Turrialba 31:287-292.

Azhar, I., G.E. Long, and M.J. Musa. 1995. Qualitative and multivariate analyses of clonal cocoa resistance to cocoa pod borer (Lepidoptera: Gracillariidae). Planter 71:307-321.

de Alba, J. and J. Basadre. 1952. Trials of fattening pigs with rations based on cacao pod meal, maize and ripe bananas. Turrialba 2:106-109.

de Alba, J., J. Garcia, F.P. Cano, and G. Ullão. 1954 Nutritive value of cacao pods in milk production in comparison with ground maize and cassava meal. Turrialba 4:29-34.

Fallahi, E., B.R. Simons, J.K. Fellman, M.A. Longstroth, W.M. Colt, and D.O. Ketchie. 1994. Tree growth and productivity and postharvest fruit-quality in various strains of 'Delicious' apple. J. Amer. Soc. Hort. Sci. 119:389-395.

Glendinning, D.R. 1966. Further observations on the relationship between growth and yield in cocoa varieties. Euphytica 15:116-127.

Hill, S.J., D.W. Stephenson and B.K. Taylor. 1987. Almond yield in relation to tree size. Scientia Hort. 33:97-111.

Larsen, F.E. and R. Fritts, Jr. 1982. Sixteen-year summary of apple rootstock influence on yield, yield efficiency, and trunk growth. J. Amer. Soc. Hort. Sci. 107:23-27.

Larsen, F.E. and R. Fritts, Jr. 1987. Hardy framework influence (1969-1983) on yield efficiency of 'Wellspur' and 'Goldspur' apple. Scientia Hort. 30:283-288.

Larsen, F.E., S.S. Higgins, and C.A. Dolph. 1992. Rootstock influence over 25 years on yield, yield efficiency and tree growth of cultivars 'Delicious' and 'Golden Delicious' apple (Malus domestica Borkh.). Scientia Hort. 49:63-70.

Lass, R.A. and L.H. Purdy. 1993. Introduction to witches' broom project, p. 1-7.In: S.A. Rudgard, A.C. Maddison, and T. Andebrhan (eds.). Disease management of cocoa. Comparative epidemiology of witches' broom. Chapman and Hall, U.K.

Lockwood, G. and J.P.T. Yin. 1996. Yields of cocoa clones in response to planting density in Malaysia. Expt. Agr. 32:41-47.

Yapp, J.H.H. 1992. A study into the potential for enhancing productivity in cocoa (Theobroma ca$c a o$ L.) through exploitation of physiological and genetic variation. PhD Diss. Univ. of Reading.

Yapp, J.H.H. and P. Hadley. 1994. Inter-relationships between canopy architecture, light interception, vigour and yield in cocoa: Implications for improving production efficiency, p. 332350. In: Proc. Intl. Cocoa Conf.: Challenges in the 90s. Malaysian Cocoa Board. 